\title{
CEMENT COMPOSITES
}

\section{REINFORCED WITH TEOS-TREATED WOOD FIBRES}

\author{
ALESSANDRA BUSS TESSARO, ${ }^{*}$ RAFAEL DE AVILA DELUCIS, ${ }^{*}$ \\ SANDRO CAMPOS AMICO ${ }^{* *}$ DARCI ALBERTO GATTO* and \\ MARGARETE REGINA FREITAS GONÇALVES* \\ "Post-Graduation Program in Materials Science and Engineering (PPGCEM), \\ Federal University of Pelotas, R. Gomes Carneiro 1, 96075-630, Pelotas, RS, Brazil \\ ${ }^{* *}$ Post-Graduation Program in Engineering of Mining, Metallurgical and Materials (PPGE3M), Federal \\ University of Rio Grande do Sul, Av. Bento Gonçalves, 9500, \\ 91501-970, Porto Alegre, RS, Brazil \\ $₫$ Corresponding author: Rafael de Avila Delucis,r.delucis@hotmail.com
}

Received July 5, 2020

In this study, wood fibres were extracted from eucalyptus and pine woods, treated by immersion in tetraethyl orthosilicate (TEOS) and incorporated into a cementitious matrix at three weight contents (2 wt $\%, 5 \mathrm{wt} \%$ and $10 \mathrm{wt} \%)$. The fibres were characterized using chemical and morphological analyses and the cement-based composites were evaluated using chemical, hygroscopic, mechanical and morphological tests. The morphological and spectroscopic results satisfactorily justified the physical-mechanical properties. The wood fibre-cement composites reached similar water uptake and apparent porosity to those of the neat mortar, but exhibited higher mechanical properties. Furthermore, all treated fibres yielded composites with improved mechanical and hygroscopic properties compared to those with pristine fibres. Overall, the best performance (based on hygroscopic and mechanical results) was obtained for the wood fibre-cement composite with $2 \mathrm{wt} \%$ pine fibres.

Keywords: wood fibres, tetraethyl orthosilicate, mortars, bio-based composites, wood-cement composites

\section{INTRODUCTION}

Fibres from natural resources have been used as raw materials in several industrial sectors, such as textile (e.g. clothing and furniture), cellulose pulping (e.g. paper, cards and packaging), pharmaceutical (e.g. compresses, bandages and medicines), and also as a constituent of engineering materials. Cement-based composites reinforced with natural fibres can be considered as promising structural materials for constructions, considering technical and environmental issues. ${ }^{1,2}$ Among the most commonly used fibres, those from forest species stand out, especially due to their large availability, low density, low cost, nonabrasive nature and low power consumption., ${ }^{3,4}$

The performance of wood fibre-cement composites is dependent on the strength of the matrix and the fibres, as well as the interface between them. However, some chemical reactions impair their physical-mechanical properties, especially when the wood cell wall is permeated by certain chemical groups as a result of cement hydration. This mechanism can be described as: (i) dissolution of lignin and hemicelluloses through the pores of the cement matrix because of the highly alkaline medium; (ii) depolymerization of cellulose chains because of hydrolysis, which reduces their degree of polymerization and mechanical strength; and (iii) deposition of lime on the wood lumen and middle lamella of the cell wall, leading to its mineralization and consequently increasing bulk brittleness. ${ }^{5,6}$

Pristine wood fibres do not generally have good affinity with cements because of their high amount of free hydroxyl groups, ${ }^{7}$ which hinder cement hydration, leading to loss in several technological properties. The same occurs for other natural fibres used as reinforcement in cement-based composites, such as bamboo, wool, coconut and sisal. ${ }^{2,5,8}$ Thus, surface pretreatments, based on silane coating, hornification, 
autoclaving, sodium silicate, potassium silicate, among others, are employed to modify the wood fibre surface. ${ }^{2,9,10}$ For a successful treatment, the chosen method needs to partly seal the fibre, and this may hinder the reactions between calcium hydroxide from the cement and the natural polymers in the wood cell wall. ${ }^{11,12}$

Previous studies reported that some silicate treatments were capable of improving hygroscopic and mechanical properties of cementbased composites. ${ }^{12}$ The most commonly applied silanes have the following chemical formula: $\mathrm{R}$ $\left(\mathrm{CH}_{2}\right)_{n}-\mathrm{Si}\left(\mathrm{OR}^{\prime}\right)_{3}$, in which $n=0-3$, where OR' is the hydrolysable alkoxy group, and $\mathrm{R}$ is the organo-functional group responsible for the chemical reaction. The reactive organofunctionality, which is usually imparted by amino, mercapto, glycidoxy, vinyl or methacryloxy groups, may form covalent bonds or just be physically compatible with the matrix. However, silanes do not have the same reaction with the $\mathrm{OH}$ groups of the fibres, since the $\mathrm{OH}$ groups of the microfibrils have very low accessibility, which demands activation of the alkoxysilane by hydrolysis, yielding reactive silanol groups. These silanol groups will then easily react with the $\mathrm{OH}$ groups of the natural fibres. ${ }^{13}$

The positive aspects of silane treatments for developing cement-based composites have been extensively reported. Tonoli et $a l .{ }^{14}$ grafted the surface of unrefined eucalyptus fibres with methacryloxypropyltri-methoxysilane,

aminopropyltri-ethoxysilane and n-octadecyl isocyanate, and reported better processing of cement-based composites, especially for methacryloxypropyltri-methoxysilane-treated

fibres, and better fibre-cement formation for noctadecyl isocyanate-treated fibres. Methacryloxypropyltri-methoxysilane- and noctadecyl isocyanate-treated fibres presented lower water retention values, while aminopropyltri-ethoxysilane increased the water retention value of the pulps and improved their capacity of hydrogen bonding. Furthermore, the potential of the methacryloxypropyltrimethoxysilane treatment was confirmed by no significant change in mechanical properties after 28 days of curing of the composites. Alkylalkoxysilane treatment of wood fibre materials (bleached hardwood pulp, unbleached recycled Kraft softwood paper bags and recycled newsprint) resulted in increased bending strength and durability of cement-based composites, but the degree of modification was dependent on the fibre characteristics. ${ }^{15}$ In addition, Bilba and Arsene treated unpyrolyzed and pyrolyzed sugar cane bagasse fibres with 0.5-8\% alkyltrialkoxysilane and dialkyldialkoxysilane, and found an influence of the silane coating in the setting time of the cement-based composites, with a positive effect of pyrolysis followed by silane treatment in improving the water resistance of the fibres. $^{16}$

Tetraethylorthosilicate (TEOS) is an ethyl ester from an orthosilicic acid, which is used as chemical precursor for several silicon-based polymers, such as siloxane. TEOS is commonly used in restoration of stone products or for corrosion protection of steel parts. The present study aims at investigating wood-cement composites of eucalyptus and pine wood fibres treated by immersion in TEOS, in comparison with wet or dried fibres. Composites with various fibre weight contents (2, 5 and $10 \mathrm{wt} \%$ ) were studied based on chemical, hygroscopic, mechanical and morphological analyses.

\section{EXPERIMENTAL \\ Wood fibres}

Fibres from Eucalyptus spp. and Pinus spp. were obtained from trees planted in homogeneous forests located in southern Brazil. The plants were about seven years old when felled. The eucalyptus fibres produced by the kraft pulping process were donated by Cellulose Rio-Grandense (CMPC) (Guaiba/Brazil). The pine fibres produced via the sulphite process were donated by Cambará S/A (Cambará do Sul/Brazil). The fibres were prepared following three routes: (i) wet - by dispersing in water at room temperature under a magnetic stirrer; (ii) dried - using an electric oven at $50{ }^{\circ} \mathrm{C}$ for $48 \mathrm{~h}$; and (iii) TEOS - impregnating with a $98 \%$ solution of tetraethyl orthosilicate.

For the TEOS treatment, the fibres (an amount of $50 \mathrm{~g}$ of dried fibres) were immersed into a simple mixture (1:1) of TEOS and absolute ethyl alcohol, and then kept under continuous mechanical stirring on a heated blanket at $50{ }^{\circ} \mathrm{C}$ until complete volatilization of the alcohol. Afterwards, $90 \mathrm{~mL}$ of TEOS was added to the fibres and they were oven-dried at $50{ }^{\circ} \mathrm{C}$ for $48 \mathrm{~h}$. Fibre morphology (diameter and length) was evaluated using an optical microscope (Opton, model PMB04). A total of 36 fibres for each species were dispersed in water for that evaluation. Water uptake was determined by the percentage of weight gain after $0.5,2$ and $24 \mathrm{~h}$ of immersion in distilled water, using analytical scales (resolution of $0.0001 \mathrm{~g}$ ). Acid-insoluble lignin (Klason lignin) content was determined based on TAPPI 249 $\mathrm{cm}-85$. For that, $1 \mathrm{~g}$ of fibre was placed in a suitable Erlenmeyer flask and then $15 \mathrm{~mL}$ of sulphuric acid 
(72\%) was added. After $2 \mathrm{~h}, 560 \mathrm{~mL}$ of water was added and the solution was autoclaved and filtered.

\section{Wood fibre-cement composites}

Mortars were formulated with cement, water and fibres. A high early strength cement (CPV ARI) was locally acquired and tap water was used. A watercement ratio equal to 0.4 was applied in all cases. Eucalyptus or pine fibres were added in variable weight fractions of $2 \mathrm{wt} \%, 5 \mathrm{wt} \%$ and $10 \mathrm{wt} \%$. All cementitious pastes were mechanically stirred and then casted into moulds to produce prismatic specimens (dimensions: $127 \mathrm{~mm}(\mathrm{~L}) \times 12.7 \mathrm{~mm}(\mathrm{~W}) \times 4.6 \mathrm{~mm}$ (T)).

Water uptake and apparent porosity were determined in accordance with ASTM C133-94. Flexural tests were carried out 7 and 28 days after moulding, using a universal testing machine (EMIC, model DL 3000). The obtained data were subjected to ANOVA tests, wherein both wood species and fibre condition were considered as factors. Micrographs of the interface between wood fibres and cement were obtained with a scanning electron microscope (Shimadzu, SSX-550 Model). Chemical composition was locally evaluated by energy dispersive spectroscopy (EDS) with a coupled microprobe.

\section{RESULTS AND DISCUSSION Properties of the fibres}

The dimensions of the eucalyptus and pine fibres were statistically different for both length $(\mathrm{F}=105.41 ; \mathrm{p}<0.05)$ and diameter $(\mathrm{F}=127.63$; $\mathrm{p}<0.05)$. The pine fibres were $114 \%$ larger (2378.39 $\mu \mathrm{m}$ and $1107.85 \mu \mathrm{m}$, respectively) and $114 \%$ wider $(50.36 \mu \mathrm{m}$ and $23.51 \mu \mathrm{m}$, respectively), compared to the eucalyptus ones. This corroborates previous studies, which found larger dimensions for fibres from gymnosperms (softwoods) compared to hardwoods, which are commonly justified by genetic characteristics. ${ }^{17}$

The biometric properties of the studied fibres are within the range reported in the literature for wood fibres from tropical climate plantations, i.e. length and diameter of, respectively, ca. $40 \mu \mathrm{m}$ and $2500 \mu \mathrm{m}$ for pine fibres, and ca. $20 \mu \mathrm{m}$ and $900 \mu \mathrm{m}$ for eucalyptus fibres. ${ }^{12,17,18}$ This suggests normal growth conditions for the trees and successful extraction of the fibres.

The mean lignin content was $1.23 \%$ and $1.65 \%$ for eucalyptus and pine fibres, respectively. These values are also within the range reported in the literature. ${ }^{19-21}$ This again indicates normal physical-chemical conditions of the fibres used in the composites.

TEOS impregnation reduced the water uptake of the eucalyptus fibres by about $33 \%$ and by $26.34 \%$ for the pine fibres (Table 1). This variation was found to be statistically significant $(\mathrm{F}=13.16 ; \mathrm{p}<0.01)$ and indicates that the treatment with TEOS was efficient regarding fibre sealing in both cases. The TEOS treatment probably blocked the hydroxyl groups from the wood fibres, which may cause a better interaction with the cement matrix. ${ }^{11,12}$ Besides, fibres with excessive moisture uptake may show poorer compatibility with the cement matrix. ${ }^{22}$

\section{Properties of the cement-based composites}

Figure 1a shows the water uptake values for the composites with eucalyptus and pine fibres, for both pristine and treated materials, as well as for the neat mortar. The greater the fibre content, the greater the water uptake, which is caused by the hydrophilic lignocellulosic nature of the fibres, related to the high content of hydroxyl groups, mostly present in amorphous polysaccharides. ${ }^{6,21}$

Regarding the fibre condition (Fig. 1b), the composites produced with wet and TEOS treated fibres presented the highest and lowest water uptakes, respectively, and the ANOVA results confirmed significant changes in water uptake $(\mathrm{F}$ $=17.52 ; \mathrm{p}<0.01)$. The highest water uptake was found for the $10 \%$ content of wet eucalyptus fibres, being $244 \%$ higher than that of the neat mortar. The lowest water uptake was observed for the composite with $2 \mathrm{wt} \%$ of TEOS-treated pine fibres, with an uptake just $11.1 \%$ higher than that of the neat mortar.

Table 1

Water uptake for pristine and treated wood fibres ${ }^{*}$

\begin{tabular}{lcccc}
\hline & $\begin{array}{c}\text { Pristine } \\
\text { eucalyptus fibre }\end{array}$ & $\begin{array}{c}\text { TEOS-treated } \\
\text { eucalyptus }\end{array}$ & $\begin{array}{c}\text { Pristine } \\
\text { pine fibre }\end{array}$ & $\begin{array}{c}\text { TEOS-treated } \\
\text { pine }\end{array}$ \\
\hline Water uptake & $0.863^{ \pm 0.08}$ & $0.536^{ \pm 0.04}$ & $0.836^{ \pm 0.04}$ & $0.620^{ \pm 0.03}$ \\
\hline Where & & &
\end{tabular}



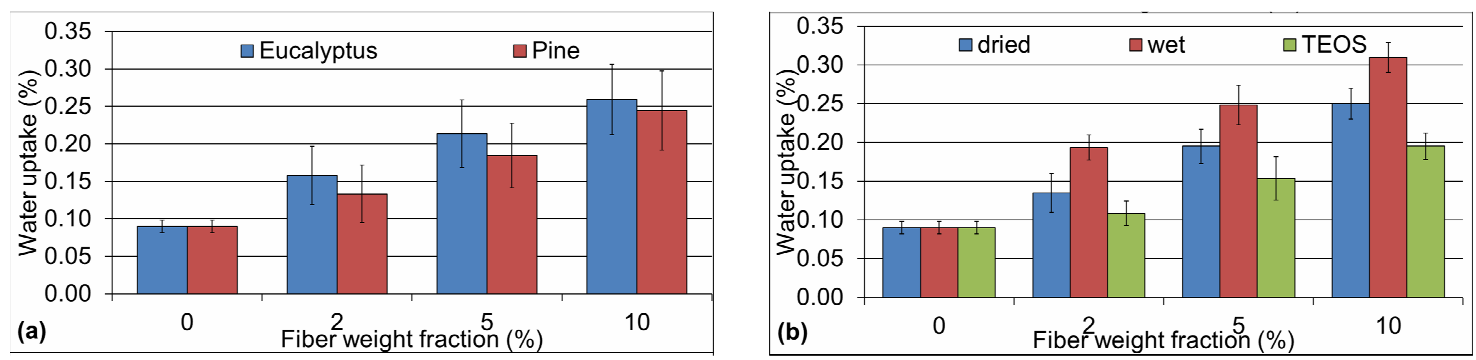

Figure 1: Water uptake for the wood fibre-cement composites by wood species (a) and fibre condition (b)
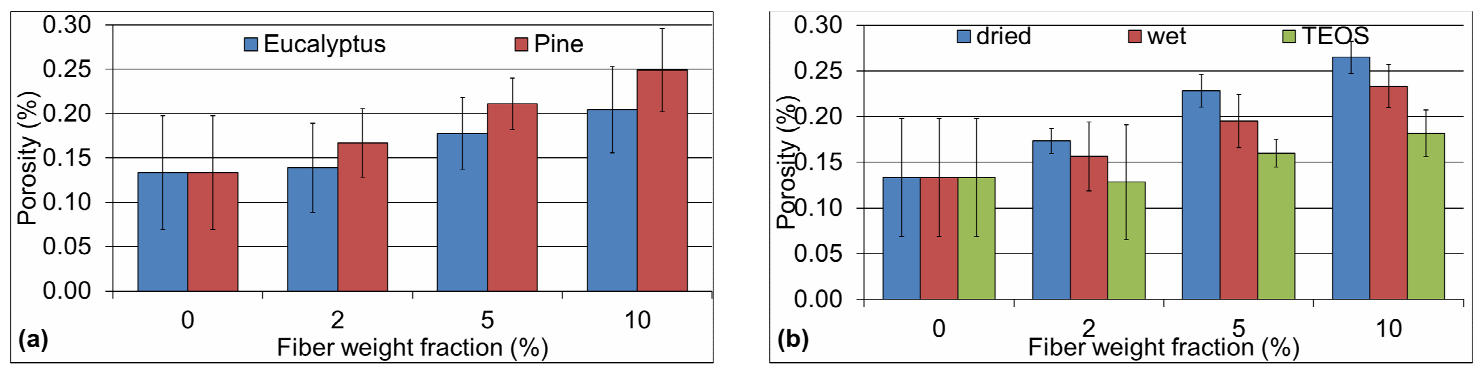

Figure 2: Apparent porosity for the wood fibre-cement composites by wood species (a) and fibre condition (b)

Therefore, even though the eucalyptus fibres exhibited lower water uptake, they did not confer greater hydrophobicity to the composites, compared to the materials with pine fibres. The composites with eucalyptus fibres presented slightly higher water uptakes, when compared to those with pine fibres, although this former fibre presented a greater effectiveness of TEOS impregnation, as aforementioned.

Regarding the apparent porosity of the composites, there were significant differences as a function of both wood species $(\mathrm{F}=6.98 ; \mathrm{p}<0.01)$ and fibre condition $(\mathrm{F}=10.84 ; \mathrm{p}<0.01)$. Figure 2 shows that the higher the fibre content, the higher the apparent porosity, i.e. the fibres increase the amount of voids in the composite. These voids are probably mostly located in the interfacial regions between the fibres and the matrix, especially if the fibres are not well dispersed and there are agglomerates. ${ }^{8,12}$

The composites produced with dried fibres and fibres treated with TEOS displayed the highest and lowest apparent porosities, respectively. This can be ascribed to the post-polymerization of TEOS in a process that may take up to 3 weeks, leading to the formation of calcium silicate hydrate during hydration of the cement, yielding strands with larger elongation. ${ }^{13}$ The composite with $10 \mathrm{wt} \%$ of dried pine fibres presented the highest porosity $(0.297 \%)$. On the contrary, the lowest porosity $(0.113 \%)$ was achieved for the composite with $2 \mathrm{wt} \%$ of TEOS-treated eucalyptus fibres. The lower apparent porosity of the material incorporating eucalyptus fibres was attributed to the easier dispersion and short geometry of these fibres. ${ }^{23}$ Shorter fibres present larger surface area and, because of that, a cementbased composite with these fibres may have more fibres per unit volume. Moreover, the microcracks formed can be partially filled by these small fibres. $^{24}$

\section{Mechanical properties of the composites}

As shown in Figure 3, all composites presented higher modulus than the neat mortar. Also, the values of modulus are in the reported range (1.0-3.3 GPa) for flexural tests in similar cement-based composites. ${ }^{1,6}$

Among the formulations, the composites with TEOS-treated fibres displayed the highest modulus $(F=10.19 ; p<0.01)$. Regardless of the fibre weight fraction, the composites with pine fibres showed significantly higher modulus than those with eucalyptus fibres $(F=4.92 ; p<0.01)$. This indicates that the eucalyptus fibre was less compatible with cement than the pine fibres, which is different from what was expected, since the eucalyptus fibres presented higher treatability. This may be attributed to differences in their main macromolecular polysaccharides, i.e. eucalyptus wood presents more hemicelluloses and less organic extractives than pine woods. Similar 
results were reported by Ashori and co-workers, who compared cement composites produced with wood fibres from a softwood (Populus) and a hardwood (eucalyptus). ${ }^{6}$

Among the composites with TEOS-treated fibres, the highest composite stiffness was reached for the $2 \mathrm{wt} \%$ fibre content of both species. Compared to the neat mortar, there are increases in modulus ascribed to the incorporation of the pine and eucalyptus fibres, which were of $21 \%$ and $41 \%$, respectively. All the composites underwent further curing after 28 days, but the composites reinforced with $2 \mathrm{wt} \%$ of wet and dried eucalyptus fibres were slightly more positively affected than that composite containing TEOS-treated fibres. This can be attributed to the lower porosity of the composites produced with 2 wt\% of fibres (Fig. 2), considering that highly alkaline water from cement hydration may degrade the polysaccharides of the natural fibres. $^{13}$
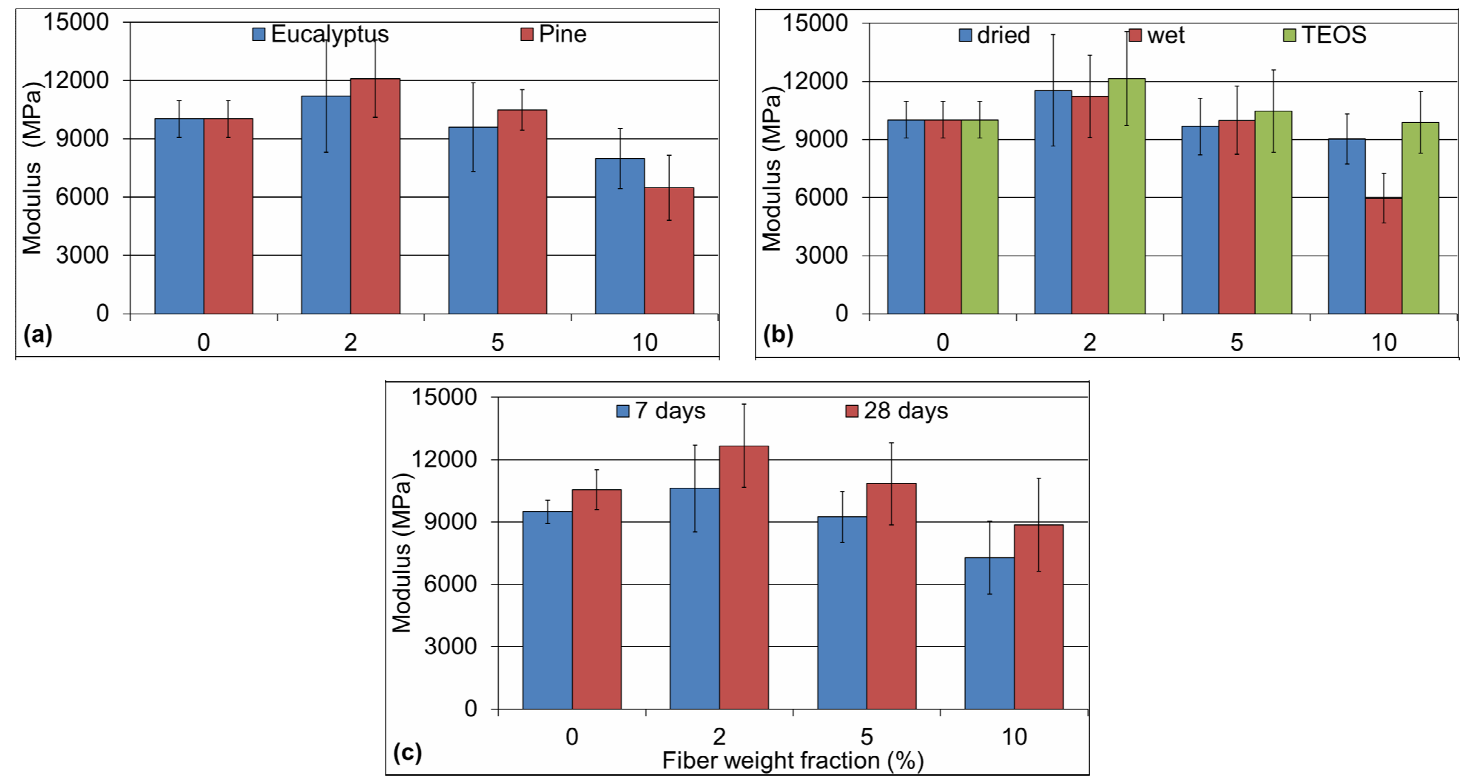

Figure 3: Modulus of elasticity for wood fibre-cement composites by wood species (a), fibre condition (b), and fibre weight fraction (c)

\section{Analysis of the composite interface}

Based on the obtained modulus values, the composites with 2 wt $\%$ of eucalyptus and pine fibres treated with TEOS were selected for the morphological analysis, along with the neat mortar for comparison purposes. For the latter, silicon, calcium, aluminium and magnesium were identified (Fig. 4 A). The same compounds were found for the composite reinforced with pine fibres (Fig. 4 C), while for the eucalyptus fibrecement composite (Fig. 4 B), sodium was also observed, being related to the kraft pulping process. ${ }^{20}$
Comparing the interfaces for the two composites, a more prominent peak associated to silicon was obtained for the eucalyptus fibres, which is attributed to the treatment with TEOS. This ratifies the water uptake results, i.e. both suggesting better TEOS impregnation in eucalyptus fibres than in pine fibres. Based on the micrographs, the pine fibres presented greater compatibility with the cement matrix, which favoured composite homogeneity and helps explaining the earlier discussed porosity and flexural modulus results. 


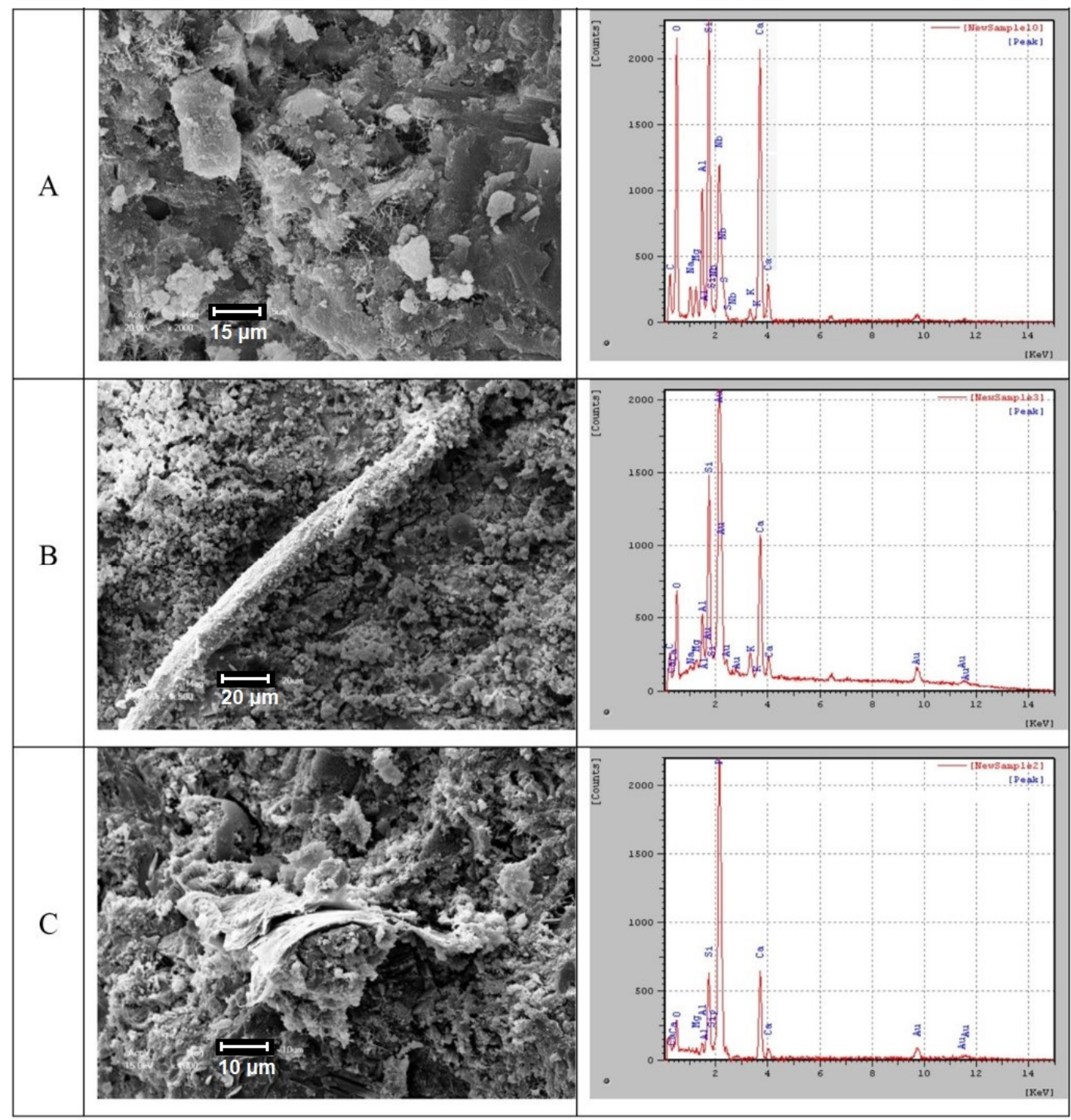

Figure 4: Micrographs and EDS diffractograms for the neat mortar (A) and the cement-based composites reinforced with eucalyptus (B) and pine (C) fibres

\section{CONCLUSION}

In the present study, eucalyptus and pine fibres were impregnated with TEOS, following a simple procedure based on immersion and stirring. This treatment presented some important effects, especially related to the sealing of the fibres, which reduced the water uptake. The eucalyptus fibres were more susceptible to the TEOS treatment than the pine ones, which may be justified by their smaller dimensions and chemical composition. Even so, the pine fibres presented greater compatibility with the cement matrix and loading $2 \mathrm{wt} \%$ of fibre yielded the composite with the best hygroscopic and mechanical performance. Furthermore, the porosity, microscopy and spectroscopy analyses helped understanding the mechanical properties of the wood-cement composites.

ACKNOWLEDGEMENTS: This work was carried out with the support of the Higher Education Personnel Improvement Coordination Brazil (CAPES) - Financing Code 001.

\section{REFERENCES}

1 A. Quiroga, V. Marzocchi and I. Rintoul, Compos. $\begin{array}{lllll}\text { B: } & \text { Eng., } & \mathbf{8 4}, & 25 & \text { (2016), }\end{array}$ https://doi.org/10.1016/j.compositesb.2015.08.069

2 J. Claramunt, M. Ardanuy, J. A. García-Hortal and R. D. T. Filho, Cem. Concr. Compos., 33, 586 (2011), 
https://doi.org/10.1016/j.cemconcomp.2011.03.003

3 A. Ashori, T. Tabarsa, K. Azizi and R. Mirzabeygi, Ind. Crop. Prod., 34, $1146 \quad$ (2011), https://doi.org/10.1016/j.indcrop.2011.03.033

4 R. de Avila Delucis, W. L. E. Magalhães, C. L. Petzhold and S. C. Amico, J. Appl. Polym. Sci., 135, 45684 (2018), https://doi.org/10.1002/app.45684

5 R. D. Tolêdo Filho, K. Scrivener, G. L. England and K. Ghavami, Cem. Concr. Compos., 22, 127 (2000), https://doi.org/10.1016/S0958-9465(99)00039-6

6 A. Ashori, T. Tabarsa and S. Sepahvand, Constr. Build. Mater., 26, $131 \quad$ (2011), https://doi.org/10.1016/j.conbuildmat.2011.06.001

7 A. Guo, Z. Sun and J. Satyavolu, Ind. Crop. Prod., 141 , 111726 (2019), https://doi.org/10.1016/j.indcrop.2019.111726

8 M. Quintero-Dávila, S. N. Monteiro and H. A. Colorado, J. Compos. Mater., 53, 883 (2019), https://doi.org/10.1177/0021998318792297

9 J. L. Pehanich, P. R. Blankenhorn and M. R. Silsbee, Cem. Concr. Res., 34, 59 (2004), https://doi.org/10.1016/S0008-8846(03)00193-5

10 K. Bilba and M.-A. Arsene, Compos. A: Appl. Sci. Manuf., $\quad 39, \quad 1488 \quad$ (2008), https://doi.org/10.1016/j.compositesa.2008.05.013

11 M. Fan, M. K. Ndikontar, X. Zhou and J. N. Ngamveng, Constr. Build. Mater., 36, 135 (2012), https://doi.org/10.1016/j.conbuildmat.2012.04.089

12 Y. Sang and J. R. Zhao, J. Compos. Mater., 49, 2757

(2015),

https://doi.org/10.1177/0021998314554123

13 Y. Xie, C. A. S. Hill, Z. Xiao, H. Militz and C. Mai, Compos. A: Appl. Sci. Manuf., 41, 806 (2010), https://doi.org/10.1016/j.compositesa.2010.03.005

14 G. H. D. Tonoli, M. N. Belgacem, G. Siqueira, J.

Bras, H. Savastano et al., Cem. Concr. Compos., 37,
68

(2013),

https://doi.org/10.1016/j.cemconcomp.2012.12.004

15 P. R. Blankenhorn, B. D. Blankenhorn, M. R. Silsbee and M. DiCola, Cem. Concr. Res., 31, 1049 (2001), https://doi.org/10.1016/S0008-8846(01)005282

16 K. Bilba and M. A. Arsene, Compos. A: Appl. Sci. Manuf., $\quad 39, \quad 1488 \quad$ (2008), https://doi.org/10.1016/j.compositesa.2008.05.013

17 J. E. M. Ballesteros, V. dos Santos, G. Mármol, M. Frías and J. Fiorelli, Cellulose, 24, 2275 (2017), https://doi.org/10.1007/s10570-017-1253-6

18 J. H. Morton, T. Cooke and S. A. S. Akers, Constr. Build. Mater., 24, $165 \quad$ (2010), https://doi.org/10.1016/j.conbuildmat.2007.08.015

19 A. Thumm and A. R. Dickson, Compos. A: Appl. Sci. Manuf., 46, 45 (2013), https://doi.org/10.1016/j.compositesa.2012.10.009

20 J. C. del Río, A. Gutiérrez, J. Romero, M. J. Martínez and A. T. Martínez, J. Anal. Appl. Pyrol., 5859, 425 (2001), https://doi.org/10.1016/S01652370(00)00126-1

21 D. Ibarra, J. C. del Río, A. Gutiérrez, I. M. Rodríguez, J. Romero et al., J. Anal. Appl. Pyrol., 74, 116 (2005), https://doi.org/10.1016/j.jaap.2004.12.009

22 E. O. Momoh and A. I. Osofero, Front. Struct. Civ. Eng., 14, 94 (2020), https://doi.org/10.1007/s11709019-0576-9

23 A. M. Barberena-Fernández, P. M. CarmonaQuiroga and M. T. Blanco-Varela, Cem. Concr. Compos., $\quad \mathbf{5 5}, \quad 145 \quad$ (2015), https://doi.org/10.1016/j.cemconcomp.2014.09.010

24 D. D. Chung, J. Mater. Civ. Eng., 17, 379 (2005), https://doi.org/10.1061/(ASCE)0899-

1561(2005)17:4(379) 